ISSN 1996-1073

www.mdpi.com/journal/energies

Article

\title{
Numerical Investigation of Hydrate Dissociation Performance in the South China Sea with Different Horizontal Well Configurations
}

\author{
Jing-Chun Feng ${ }^{1,2,3}$, Xiao-Sen $\mathrm{Li}^{1,2, *}$, Gang $\mathrm{Li}^{1,2}$, Bo Li ${ }^{1,2,3}$, Zhao-Yang Chen ${ }^{1,2}$ and Yi Wang ${ }^{1,2}$ \\ 1 Guangzhou Center for Gas Hydrate Research, Chinese Academy of Sciences, Guangzhou 510640, \\ China; E-Mails: fengjc@ms.giec.ac.cn (J.-C.F.); ligang@ms.giec.ac.cn (G.L.); \\ libo@ms.giec.ac.cn (B.L.); chenzy@ms.giec.ac.cn (Z.-Y.C.); wangyi@ms.giec.ac.cn (Y.W.) \\ 2 Key Laboratory of Renewable Energy, Guangzhou Institute of Energy Conversion, \\ Chinese Academy of Sciences, Guangzhou 510640, China \\ 3 University of Chinese Academy of Sciences, Beijing 100083, China \\ * Author to whom correspondence should be addressed; E-Mail: lixs@ms.giec.ac.cn; \\ Tel.: +86-20-8705-7037; Fax: +86-20-8703-4664.
}

Received: 4 April 2014; in revised form: 3 July 2014 / Accepted: 16 July 2014 /

Published: 28 July 2014

\begin{abstract}
Based on the available measurement data and literature on the hydrate deposits of the South China Sea, a numerical simulation with a new dual horizontal well system has been carried out. Warm brine stimulation combined with depressurization is employed as the production method. Two horizontal wells were situated in the same horizontal plane and they were placed in the middle of the Hydrate-Bearing Layer (HBL). The warm brine is injected from the left well (LW) into the reservoir, and the right well (RW) acted as the producer under constant pressure. The simulation results show that the effects of hydrate dissociation rate, gas to water ratio, and energy ratio are all better than the previous work in which the dual horizontal wells are placed in the same vertical plane. In addition, the sensitivity analysis indicates that a higher injection rate can enhance the hydrate dissociation rate and gas production rate, while a lower injection rate gives a more favorable gas to water ratio and energy ratio.
\end{abstract}

Keywords: marine hydrate; gas production; depressurization; warm brine stimulation; dual horizontal wells; South China Sea 


\section{Introduction}

Natural gas hydrates are solid crystalline compounds which are formed by water molecules with small guest molecules under suitable conditions of high pressure and low temperature [1]. The most typical hydrate-forming gas is methane, and natural gas hydrates are found widely distributed in the permafrost region and in oceanic accumulations. Current estimations of the hydrate-containing hydrocarbon gas available at standard conditions ranges from $10^{15}$ to $10^{18} \mathrm{~m}^{3}$, which is twice as much as the conventional fossil energy [2]. The attractiveness of gas hydrates as a potential future energy source is increasing on account of the abundance of the resource and the growing global energy demands.

There are four main methods for exploiting hydrate from hydrate accumulations: depressurization [3-7], thermal stimulation [8-13], inhibitor stimulation [14-17], and carbon dioxide replacement [18,19]. The depressurization method has received considerable attention for hydrate dissociation because of its easy operation and high energy efficiency. Nevertheless, secondary hydrate formation always occurs in the dissociation process by single depressurization because of the cooling effect, and the gas production rate is quite low when the heat transfer from the reservoir is limited [2]. The experimental investigations of $\mathrm{Li}$ et al. [20] indicate that the combination of depressurization and thermal stimulation is favorable for hydrate dissociation. In addition, the combination of depressurization and thermal stimulation has been verified to be a possible method to obtain energy from the permafrost hydrates in the Mallik 2002 well [1].

In recent years, research has shown that there are rich gas hydrate resources in the South China Sea region (SCS, Figure 1) [21-24]. Gas hydrate samples were gathered in the Shenhu Area of the South China Sea during the scientific expedition conducted by the China Geologic Survey in May 2007 [24]. Li et al. [10] investigated the gas production performance by the huff and puff method with a single horizontal well in the Shenhu Area, and the results showed that the gas production rate was lower than the acceptable standard for commercial gas production. Similar results were obtained by Su et al. [25] when a numerical simulation was conducted by the huff and puff method with a single vertical well. In general, previous researches have demonstrated that a single horizontal well or a vertical well are not favorable for gas production from the South China Sea, making it important to consider other well designs, including multi-well configurations. The dual horizontal well system (shown in Figure 2) is a common well configuration in hydrate deposits. The two wells are situated in the same vertical plane in Pattern i, and they are placed in the same horizontal plane in Pattern ii. The gray section shown in Figure 2 represents the whole reservoir because of symmetry. Consequently, each single unit in Figure 2 includes an upper well and a lower well in the same vertical plane in Pattern i, and each unit in Pattern ii contains a left well and a right well in the same horizontal plane. As each single unit represents the same region of hydrate reservoir, each pair of injection well and production well stands for the same region of the hydrate reservoir in Pattern $i$ and Pattern ii. Feng et al. [26] carried out a numerical simulation with Pattern i of gas production in the South China Sea by the depressurization combined with warm brine stimulation method. In their work, the injected warm brine can be pumped out directly from the upper well at the 118th day when the hydrate between the two wells is completely dissociated, then the effect of warm brine stimulation on gas production is weakened. 
Figure 1. Map of the South China Sea [18].

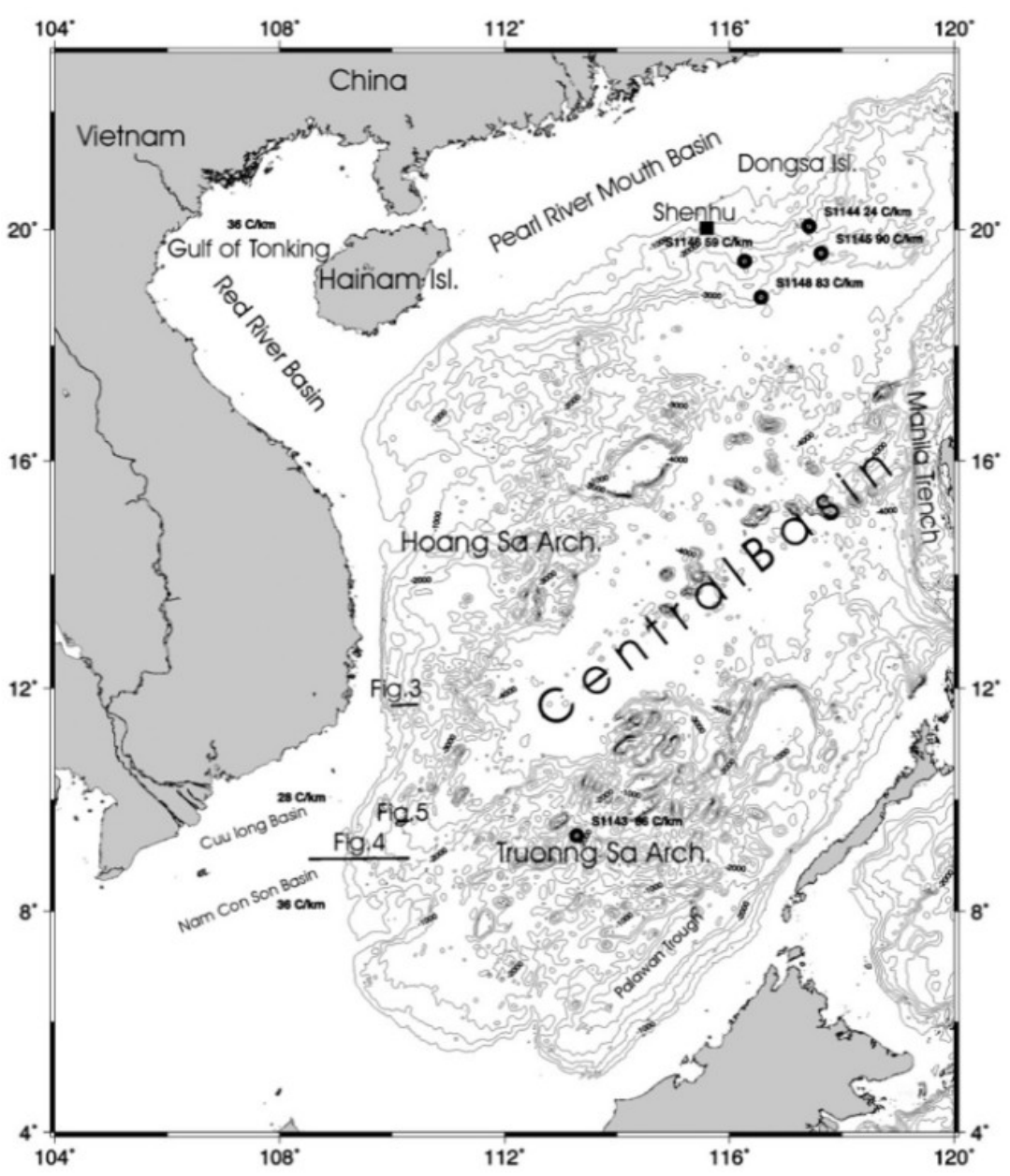

Figure 2. Well configuration of the dual horizontal well system in the hydrate deposit.

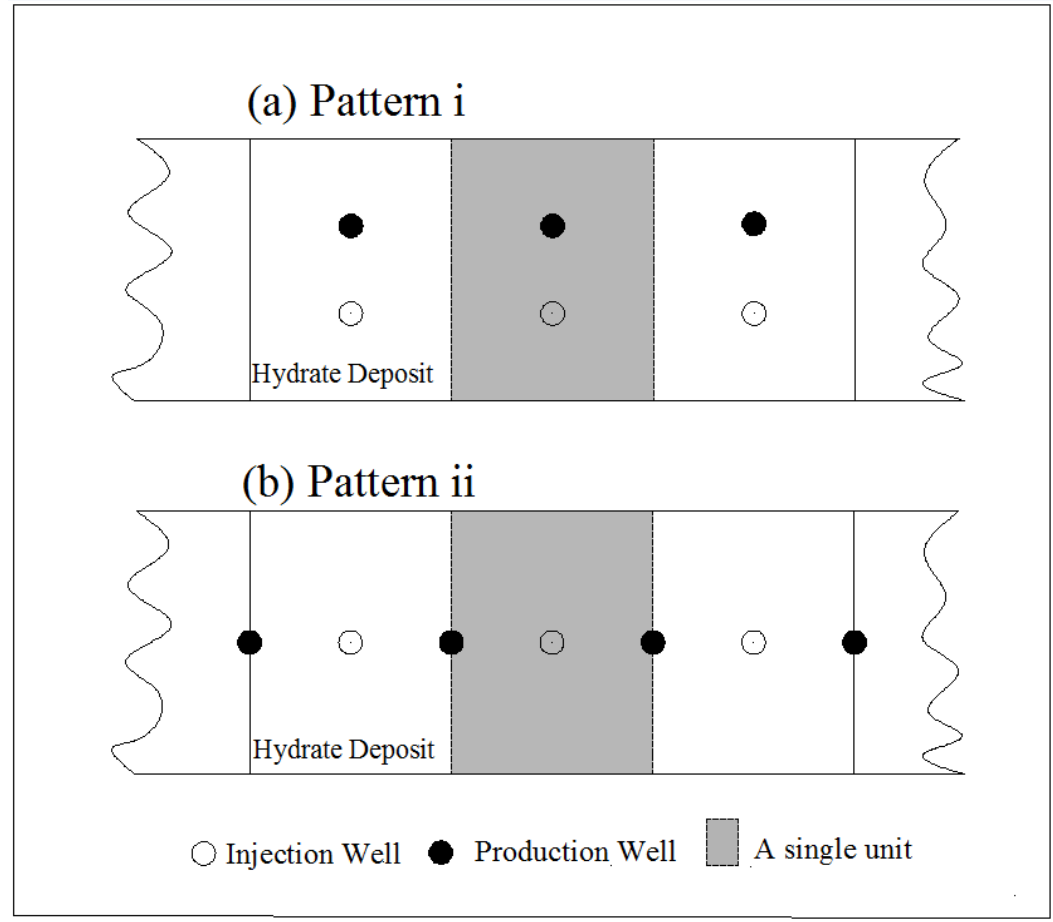


The main objective of this study is to investigate the effect of the new dual horizontal well system on gas production from the South China Sea. First a model of a gas hydrate reservoir in the South China Sea is established according to the available data. Based on a previous study [26], a new dual horizontal well system (Pattern ii shown in Figure 2b) is constructed. In this work, the method of depressurization combined with warm brine stimulation is employed. The effects of the previous well configurations and the novel pattern have been compared. In addition, the sensitivity of gas production to the warm brine injection rate is also investigated.

\section{Production Strategies and Simulation Approach}

\subsection{Production Methods and Well Design}

The new dual horizontal well configuration shown in Figure 3a is applied for gas production from marine hydrate accumulations in the South China Sea. The hydrate reservoir in the South China Sea is similar to a Class 3 hydrate deposit which only consists of a hydrate-bearing layer (HBL) [27]. Konno et al. [6] indicated that single depressurization was unpractical for gas production from this kind of hydrate deposit. Li et al. [20] demonstrated by experimental investigation that depressurization combined with thermal stimulation was profitable for gas production. Moreover, Li et al. [10] showed that the increase of injection temperature had a limited effect on hydrate dissociation. Feng et al. [26] further indicated that warm brine injection had a higher energy ratio than the high-temperature brine injection.

Figure 3. (a) Schematic of the marine hydrate reservoir in the South China Sea; (b) the corresponding 2-D hybrid mesh.

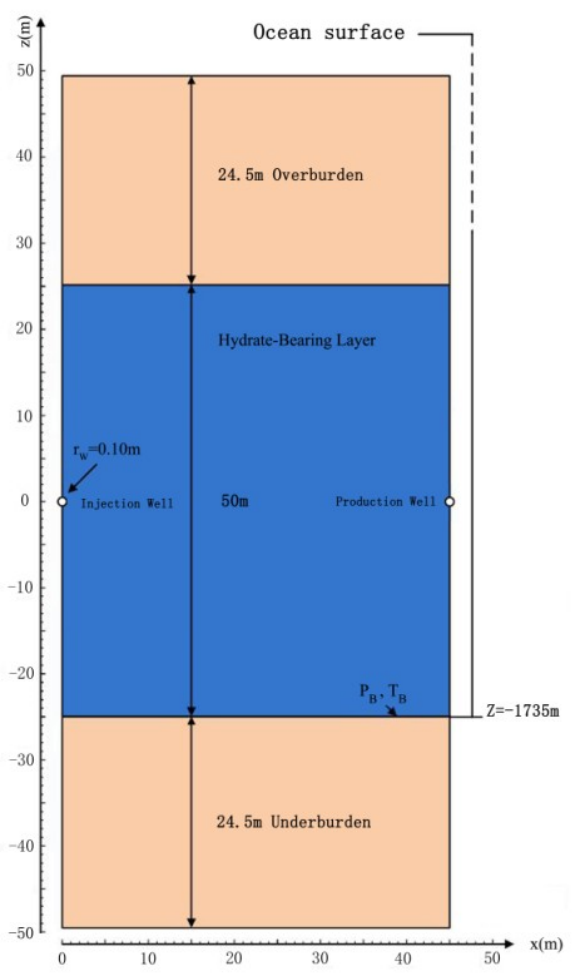

(a)

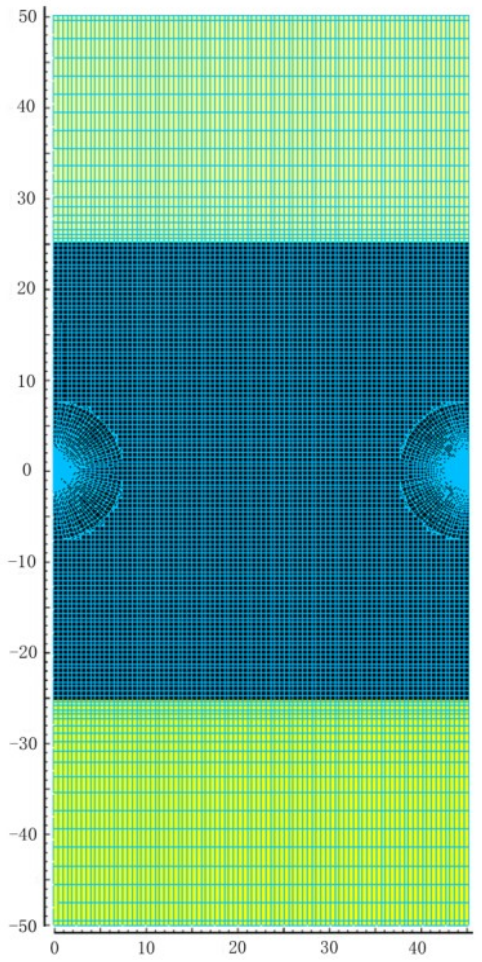

(b) 
In this work, warm brine stimulation combined with depressurization is employed for gas production from the hydrate reservoir. As shown in Figure 3a, there are two horizontal wells situated in the same horizontal plane. The left horizontal well (LW) acts as the injector where warm brine is injected into the HBL. Meanwhile, gas and water are pumped out from the right horizontal well (RW) which is conducted under constant-P production. The driving force of depressurization is the same as the previous work [26], in which $\Delta P_{\mathrm{W}}\left(\Delta P_{\mathrm{W}}=P_{\mathrm{W} 0}-P_{\mathrm{W}}\right)$ is $0.44 P_{\mathrm{W} 0} . P_{\mathrm{W}}=9.73 \mathrm{MPa}$ is the constant well pressure, and $P_{\mathrm{B}}=17.47 \mathrm{MPa}$ is the initial pressure of the $\mathrm{HBL}$ at the location of the horizontal well.

\subsection{Geometry, Domain Discretization, and System Properties}

The system properties and geological data which are originated from the limited field measurement data and the literature data are displayed in Table 1.

Table 1. Physical properties and simulation models in marine deposit of the South China Sea.

\begin{tabular}{|c|c|c|c|}
\hline Parameter & Value & Parameter & Value \\
\hline Thickness of HBL & $50 \mathrm{~m}$ & Capillary pressure & $P_{\text {cap }}=-P_{01}\left[\left(S^{*}\right)^{-1 / \lambda}-1\right]^{1-\lambda}$ \\
\hline Thickness of OB and UB & $24.5 \mathrm{~m}$ & model $[28]$ & $S^{*}=\left(S_{\mathrm{A}}-S_{\mathrm{irA}}\right) /\left(S_{\mathrm{mXA}}-S_{\mathrm{irA}}\right)$ \\
\hline $\begin{array}{l}\text { Position of HBL } \\
\text { below the ground }\end{array}$ & $160.5 \mathrm{~m}$ & $S_{\text {irA }}$ & 0.29 \\
\hline Distance between two wells & $45 \mathrm{~m}$ & $\lambda$ & 0.45 \\
\hline $\begin{array}{l}\text { Initial } P_{\mathrm{B}} \text { and } T_{\mathrm{B}} \\
\text { (at base of HBL) }\end{array}$ & $\begin{array}{l}17.47 \mathrm{MPa}, \\
289.08 \mathrm{~K}\end{array}$ & $P_{01}$ & $10^{5} \mathrm{~Pa}$ \\
\hline Sea floor temperature $T_{0}$ & $277.15 \mathrm{~K}$ & $\begin{array}{l}\text { Relative permeability } \\
\text { Model [29] }\end{array}$ & $\begin{array}{c}k_{\mathrm{rA}}=\left(S_{\mathrm{A}}{ }^{*}\right)^{n} \\
k_{\mathrm{rG}}=\left(S_{\mathrm{G}}{ }^{*}\right)^{n G} \\
S_{\mathrm{A}}{ }^{*}=\left(S_{\mathrm{A}}-S_{\mathrm{irA}}\right) /\left(1-S_{\mathrm{irA}}\right) \\
S_{\mathrm{G}}{ }^{*}=\left(S_{\mathrm{G}}-S_{\mathrm{irG}}\right) /\left(1-S_{\mathrm{irA}}\right)\end{array}$ \\
\hline Geothermal gradient $G$ & $0.045 \mathrm{~K} / \mathrm{m}$ & $n$ & 3.572 \\
\hline Water salinity (mass fraction) & $3.50 \%$ & $n_{\mathrm{G}}$ & 3.572 \\
\hline $\begin{array}{c}\text { Intrinsic permeability } \\
k_{\mathrm{x}}=k_{\mathrm{y}}=k_{\mathrm{z}}(\mathrm{HBL}, \mathrm{OB} \& \mathrm{UB})\end{array}$ & $\begin{array}{c}7.5 \times 10^{-14} \mathrm{~m}^{2} \\
(=75 \mathrm{mD})\end{array}$ & $S_{\mathrm{irG}}$ & 0.05 \\
\hline Porosity $\phi$ (all formations) & 0.40 & $S_{\mathrm{irA}}$ & 0.30 \\
\hline Initial hydrate saturation & $S_{\mathrm{H}}=0.451$ & $\begin{array}{c}\text { Composite thermal } \\
\text { conductivity model [29] }\end{array}$ & $\begin{array}{c}k_{\Theta \mathrm{C}}=k_{\Theta \mathrm{RD}}+\left(S_{\mathrm{A}}^{1 / 2}+S_{\mathrm{H}}^{1 / 2}\right) \\
\left(k_{\Theta \mathrm{RW}}-k_{\Theta \mathrm{RD}}\right)+\phi S_{\mathrm{I}} k_{\Theta \mathrm{I}}\end{array}$ \\
\hline
\end{tabular}

For this numerical simulation study, the parallel version of the TOUGH + HYDRATE $(T+H)$ code is employed [29]. This code contains a kinetic and an equilibrium model for hydrate formation and dissociation. By using the experimental data from a cubic hydrate simulator and a pilot-scale hydrate simulator, Li et al. [30,31] have verified the validity of the models of the $\mathrm{T}+\mathrm{H}$, and they have also modified the model.

The hydrate reservoir extends from $1660.5 \mathrm{~m}$ to $1759.5 \mathrm{~m}$ below sea level. The distance from the seafloor to the top of the overburden is $160.5 \mathrm{~m}$. The properties of the overburden and underburden are the same as the HBL. The pressure and temperature of the boundaries above the overburden and below the underburden are set as constant. The radii of the two wells $r_{\mathrm{W}}$ is $0.1 \mathrm{~m}$. Twelve grooves are evenly 
distributed along the surface of the well to permit fluids to flow from the reservoir into the well [32]. For both wells, the porosity $\varphi$; the permeability $k$; and the capillary pressure $P_{\text {cap }}$ are assumed to be $1,5.0 \times 10^{-9} \mathrm{~m}^{2}$ (5000 Darcies), and 0, respectively.

Figure $3 \mathrm{a}$ shows the geometry and the configuration of the hydrate deposit with a new dual horizontal well system. It contains a $50 \mathrm{~m}$-thick hydrate-bearing layer which is sandwiched by a permeable overburden and an underburden. Both of the overburden and the underburden are $24.5 \mathrm{~m}$, which is large enough for heat and mass exchange with the HBL. The dual horizontal wells are located at $z=0 \mathrm{~m}$, and the $x$ coordinates of the LW and the RW are $0 \mathrm{~m}$ and $45 \mathrm{~m}$, respectively. Figure 3a shows that the simulation region in this work is $0 \leq x \leq 45 \mathrm{~m}$, which indicates a well spacing of $90 \mathrm{~m}$ in a single unit in Figure $2 \mathrm{~b}$ because of symmetry.

Figure $3 \mathrm{~b}$ displays the unstructured hybrid grid of the hydrate deposit. It includes 12,228 elements, which are located in the region of $0 \leq x \leq 45 \mathrm{~m},-49.5 \mathrm{~m} \leq x \leq 49.5 \mathrm{~m}$. The single unit of length $\Delta y$ is $1 \mathrm{~m}$ by assuming that the behavior along the horizontal well is uniform. The elements of the overburden and the underburden are set as inactive boundaries, which are responsible for the exchange of heat and mass transfer with the HBL. There are six gridblocks in the first cylindrical layer $(r=0.1 \mathrm{~m})$, which represent the grooves of the well. The warm brine is injected into the reservoir from these gridblocks in the LW at a constant injection rate, and the pressure of such gridblocks in the RW is set as constant pressure which is lower than the initial pressure.

\section{Simulation Results}

\subsection{Spatial Distributions of the New Well Configuration in the Reference Case}

A new well configuration in which the dual horizontal wells are situated in the same horizontal well plane is employed to produce gas from the marine hydrate deposit in the South China Sea. Due to symmetry, only a half injection well (LW) and a half production well (RW) are considered. Cases of different warm brine injection rates $Q_{\text {inj }}$ are considered. In order to insure the safety of the operation, the LW is conducted under depressurization with the same pressure drop as the RW in the initial 40 days, and then the warm brine is injected into the reservoir from the LW.

In this section and the next section, we only consider the production behaviors of the reference case. In the reference case, the injection rate and the injection temperature of the warm brine are set as $3.6 \mathrm{~kg} / \mathrm{s}$ and $28{ }^{\circ} \mathrm{C}$, respectively. The mass fraction of inhibitor in the injected brine is $3.5 \%$. The sensitivity analysis of the injection rate will be discussed in Section 3.4.

\subsubsection{Spatial Distribution of $S_{\mathrm{H}}$ and $S_{\mathrm{G}}$}

Figures 4 and 5 show the spatial distributions of the hydrate saturation $S_{\mathrm{H}}$ and the gas saturation $S_{\mathrm{G}}$ in the whole deposit during gas production of 30 years for the reference case, respectively. 
Figure 4. Evolution of the spatial distribution of $S_{\mathrm{H}}$ during 30-year production in the South China Sea.

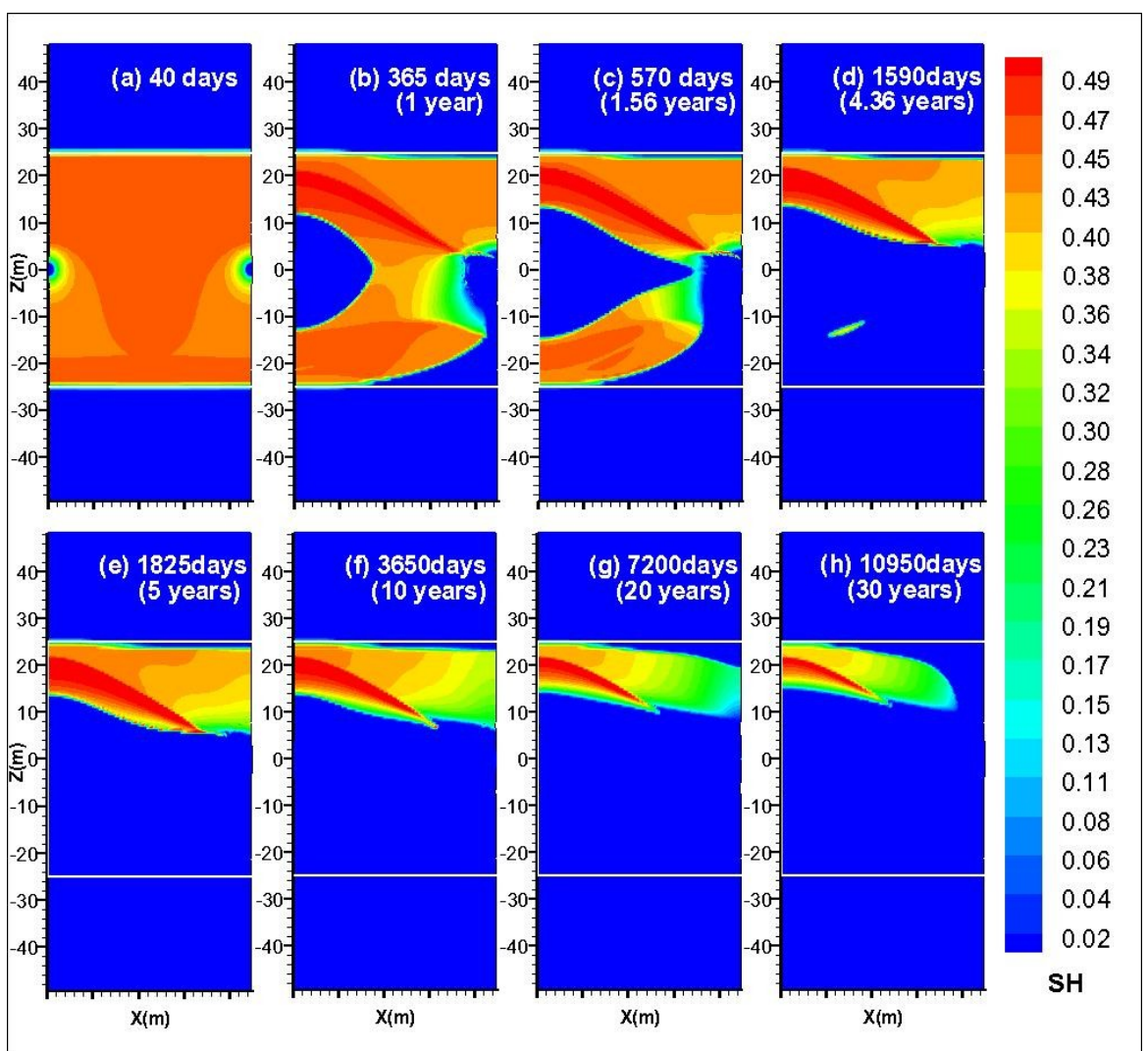

Figure 5. Evolution of the spatial distribution of $S_{\mathrm{G}}$ during 30-year production in the South China Sea.

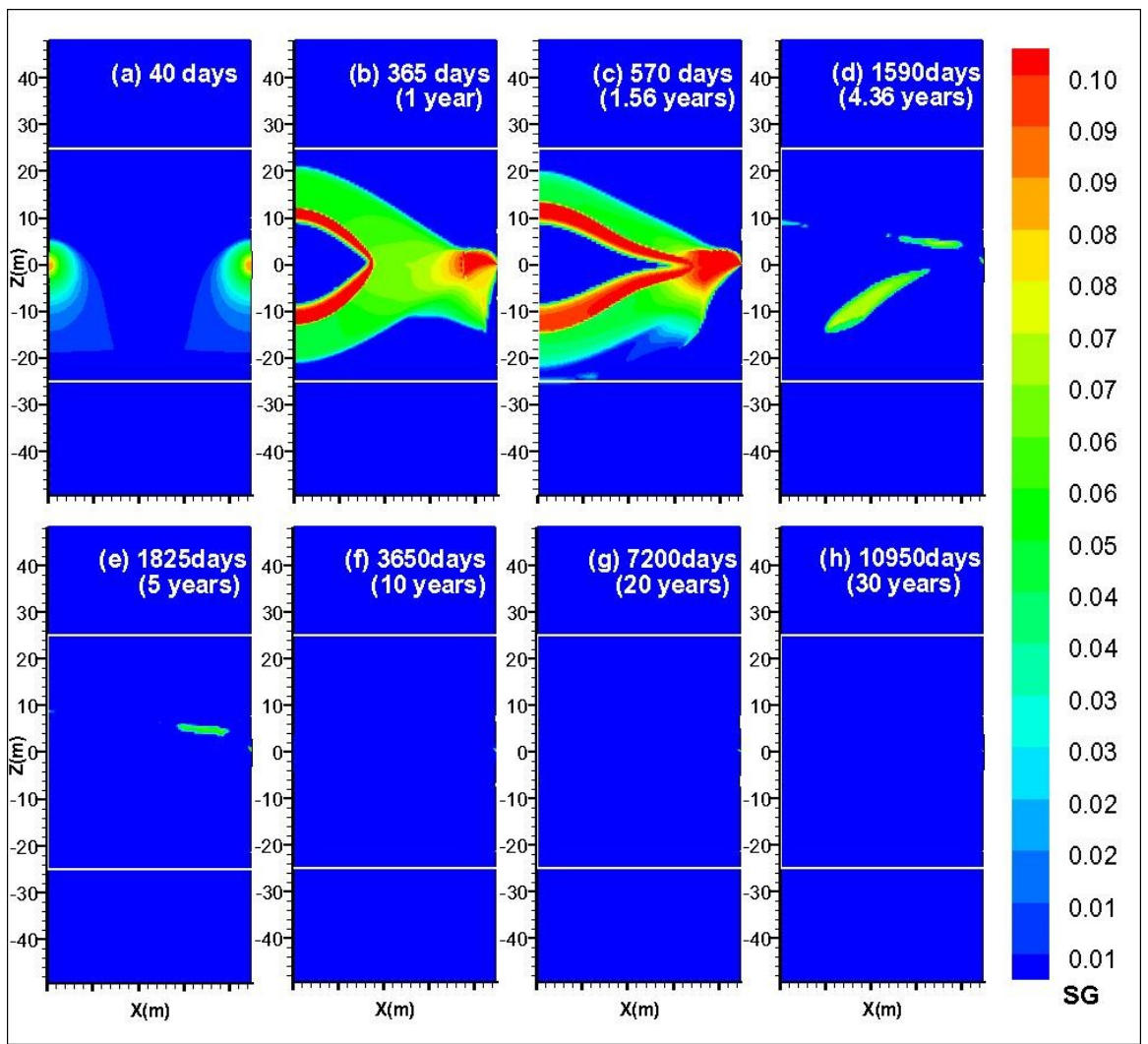


As shown in Figure 4a, two symmetrical cylindrical dissociation interfaces emerge around the two wells after 40-day production by the depressurization method. Figure 5a shows that two bulks of dissociated gas accumulate around the two wells during this period. Figure $4 \mathrm{~b}$ shows that when the warm brine is injected into the reservoir, the dissociation interface around the LW grows quickly, and it changes into a conical interface at the end of the first year. Under the stimulation of depressurization, the dissociation front around the RW enlarges and spreads to the bottom of the HBL. As shown in Figure 5b,c, a considerable amount of gas is accumulated around the LW, and the gas is transferred from the LW to the RW under the effects of the pressure gradient. Secondary hydrate occurs in the leading edge of the dissociation front. The reason is that the dissociated gas accumulates in this area and the local pressure and temperature meet the conditions of hydrate formation. Figure $4 \mathrm{c}$ shows that the dissociation front expands from the LW into the deep part of the reservoir on account of warm brine injection, and it connects the dissociation front near the RW at the 570th day (1.56 years). It is displayed in Figure $4 \mathrm{~d}$ that the hydrate located below the wells (in the area of $-45 \leq x \leq 0 \mathrm{~m}$ ) has been dissociated completely in 1590 days (4.36 years). Meanwhile, the free gas is pumped out from the RW directly (shown in Figure 5d). After 1590 days, the injected warm brine can flow from the LW to the RW directly. It is shown in Figure $4 \mathrm{e}-\mathrm{h}$ that there is little variation in the spatial distribution of $S_{\mathrm{H}}$ in the entire reservoir from the 5th year to the 10th year. This is because the effect of warm brine stimulation is weakened as the warm brine can flow toward the production well with little obstruction in the later 25 years. There is little free gas remained in the reservoir after 5-year production (shown in Figure 5e). The secondary hydrate and the originated hydrate in the reservoir play a significant role in hindering the diffusion of the free gas. Therefore, there is almost no free gas remaining in the reservoir as the hydrate located below the wells is dissociated completely (shown in Figure $5 \mathrm{f}-\mathrm{h}$ ).

\subsubsection{Spatial Distribution of $X_{\mathrm{S}}$}

Figure 6 shows the spatial distribution of the inhibitor saturation $X_{\mathrm{S}}$ in the entire deposit during 30 years of gas production in the reference case. Figure 6a shows that $X_{\mathrm{S}}$ around the two wells decreases due to the dilution by the free water caused by hydrate dissociation. When the warm brine is injected into the reservoir, the dissociation rate increases drastically and more free water is released from the hydrate. It results in the $X_{\mathrm{S}}$-reduction region expands around the well (Figure $6 \mathrm{~b}$ ). Figure $6 \mathrm{c}$ displays that the dilution zone transfers from the LW to the RW with the dissociation front expands into the deep part of the reservoir (shown in Figure 4c). When the two wells are totally connected, the free water can be pumped out from the RW instantly, thus the dilution zone almost disappears in the later 25 years (shown in Figure 6d-h).

\subsubsection{Spatial Distribution of $P$}

Figure 7 shows the spatial distribution of the pressure $P$ in the entire deposit during 30 years of gas production in the reference case. As shown in Figure 7a, two symmetrical cylindrical pressure gradients appear around the two wells. When the warm brine is injected into the reservoir, the pressure around the LW rises instantly because of the temperature increase and the free gas accumulation. On the other hand, the pressure decrease area expands under the driving force of depressurization. 
Hence, the difference of pressure between the two wells increases over time. When the two wells are connected, such a high pressure difference disappears gradually (shown in Figure 7c).

Figure 6. Evolution of the spatial distribution of $X_{\mathrm{S}}$ during 30-year production in the South China Sea.

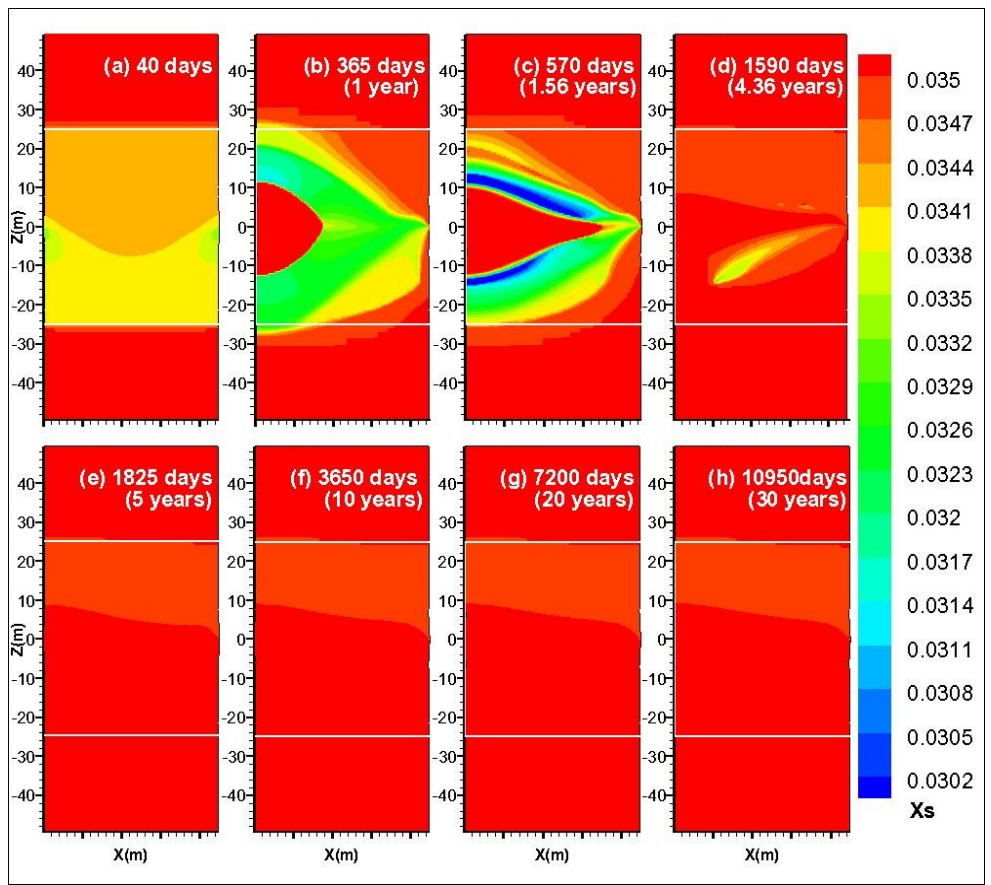

Figure 7. Evolution of the spatial distribution of $P$ during 30 -year production in the South China Sea.

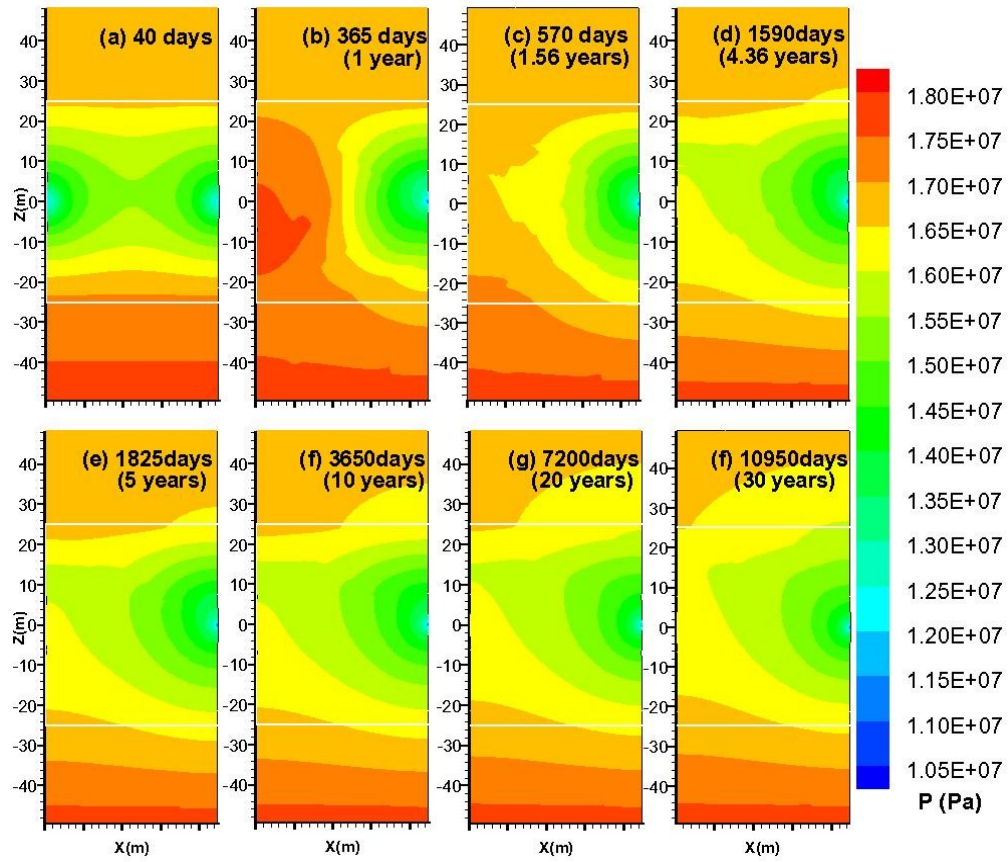

The pressure reduction region expands to the entire hydrate reservoir when the hydrate below the wells are dissociated completely (Figure 7d), and the spatial distribution of pressure in the reservoir changes little in the following 25 years. 


\subsubsection{Spatial Distribution of $\mathrm{T}$}

Figure 8 demonstrates the spatial distribution of the temperature $T$ in the entire deposit during 30 years of gas production in the reference case.

Figure 8. Evolution of the spatial distribution of $T$ during 30 -year production in the South China Sea.

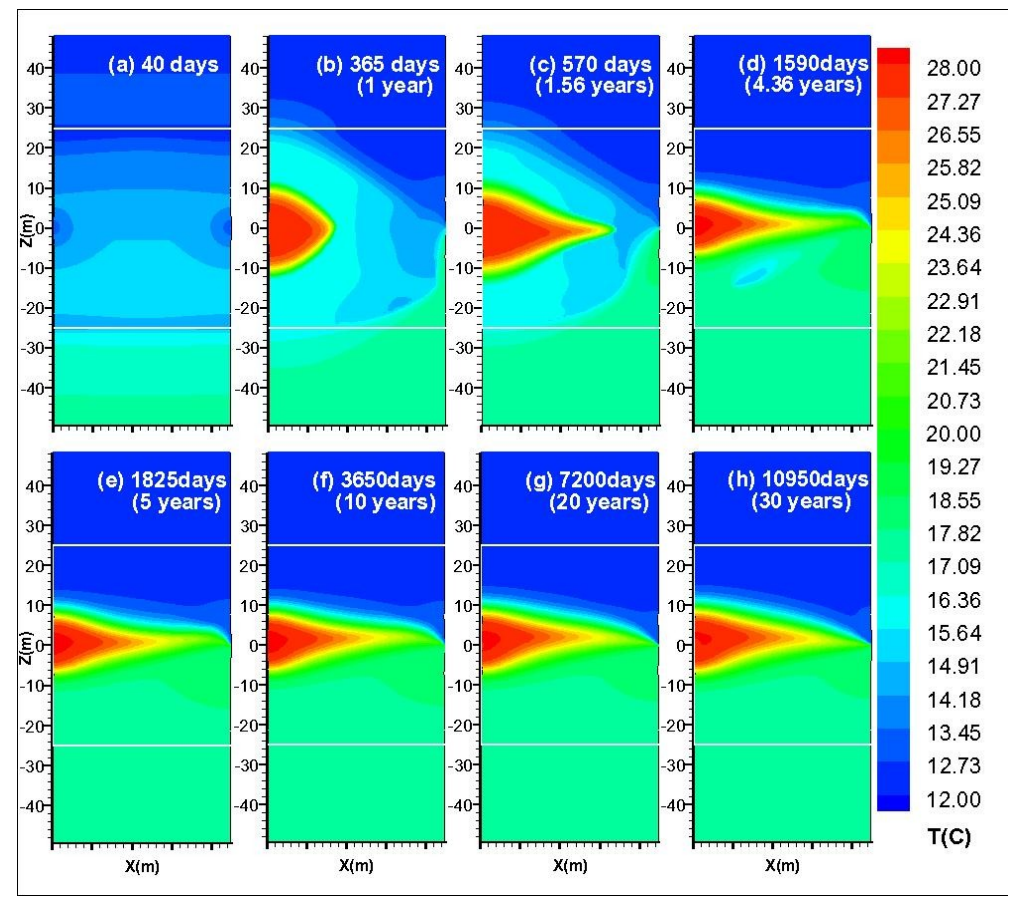

At the end of the 40-day depressurization process, the temperatures around the two wells decrease caused by the cooling effect of depressurization. Subsequently, the warm brine is injected into the reservoir, resulting in temperature growth around the LW. The high-temperature region spreads from the LW to the right RW under the promotion of warm brine flow. In addition, the warm brine which is originated from the underburden flows to the RW under the driving force of depressurization. When the two wells are connected totally, the temperatures of the region located in the same latitude with the two wells are almost above $28{ }^{\circ} \mathrm{C}$. Furthermore, all of the temperatures in the reservoir below the two wells increase because of the warm brine flow.

\subsection{Production Behaviors with the New Horizontal Well System in the Reference Case}

\subsubsection{Gas Production}

Figure 9 shows the evolution of the cumulative volume of the produced gas $V_{\mathrm{P}}$ and the dissociated gas $V_{\mathrm{R}}$ for the reference case during 30 -year production. It is shown that hydrate dissociation can be divided into three stages: (a) from the 41st day to the 570th day, hydrate is dissociated rapidly under the combination of depressurization and warm brine stimulation, resulting in the rapid growth of the cumulative volume of the produced gas and the dissociated gas. During this section, $V_{\mathrm{R}}$ is larger than $V_{\mathrm{P}}$. The reason is that the dissociated gas accumulated in the hydrate reservoir before the two wells are connected (shown in Figure 5b,c); (b) From the 570th day to the 1590th day, the warm brine flows 
quickly to the production well as the two wells are connected (shown in Figure 4c), and it causes the reduction of hydrate dissociation rate. During this section, $V_{\mathrm{R}}$ is smaller than $V_{\mathrm{P}}$. This indicates that some of the produced gas is originated from the dissolved gas in the sea water; (c) At the 1590th day, there's little obstruction in the reservoir as the hydrate around the wells and below the wells is dissociated completely (shown in Figure 4d). Therefore, the warm brine flows through the reservoir directly, and the dissociation rate decreases drastically. The percentage of dissociated hydrate is $70.5 \%$ at the 1590th day (4.36 years), indicating that most of the hydrate has been dissociated in less than 5 years with the new horizontal well system. The total volume of the produced gas in 30 years is $3.28 \times 10^{5} \mathrm{ST} \cdot \mathrm{m}^{3}$. For a well spacing of $90 \mathrm{~m}$, and a well length of $1000 \mathrm{~m}$, the average gas production rate is $1.80 \times 10^{6} \mathrm{ST} \cdot \mathrm{m}^{3} /$ day. Comparing with the commercially viable production rate $\left(2.8 \times 10^{5} \mathrm{ST} \cdot \mathrm{m}^{3} /\right.$ day $)$ in the Gulf of Mexico [33], gas production in this work is favorable.

Figure 9. Evolution of cumulative volume of the produced gas $V_{\mathrm{P}}$ and the dissociated gas $V_{\mathrm{R}}$ for the reference case during 30-year production.

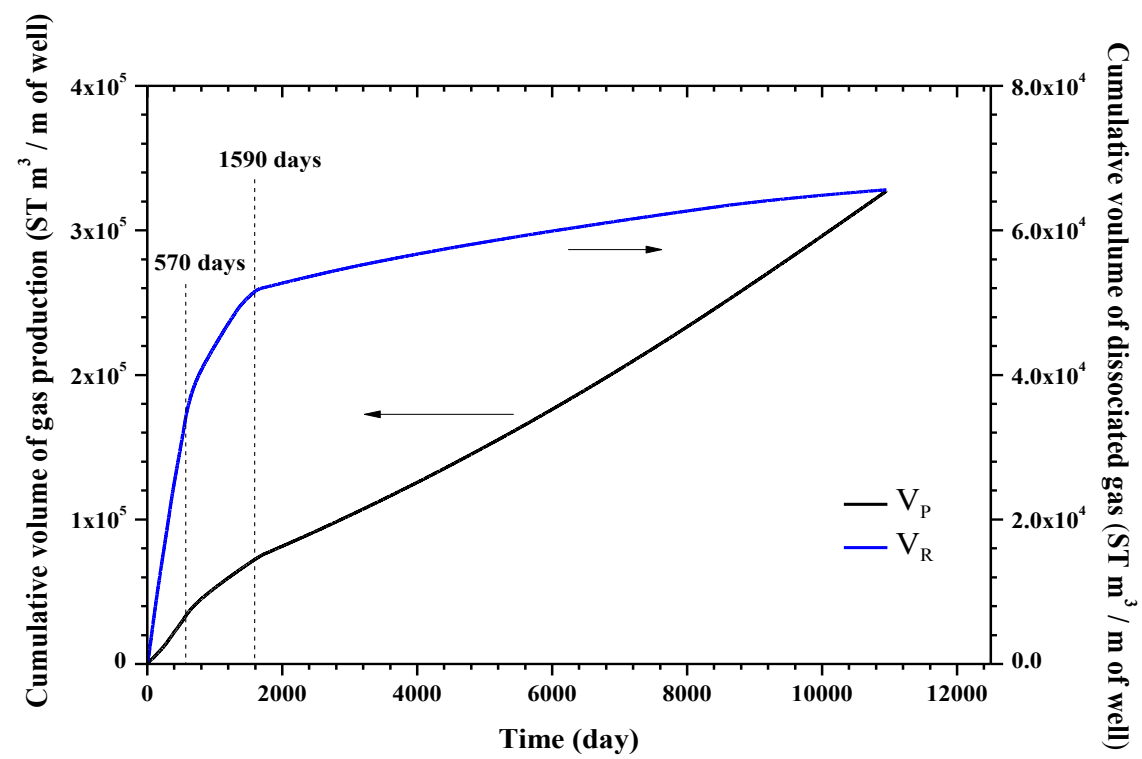

\subsubsection{Water Production and Gas to Water Ratio}

Figure 10 shows the evolution of the cumulative mass of water production $M_{\mathrm{W}}$ and gas to water ratio $R_{\mathrm{GW}}$ for the reference case during 30 -year production. The gas to water ratio $R_{\mathrm{GW}}$ is defined as the volume ratio of the produced gas $\left(V_{\mathrm{P}}\right)$ and the produced water $\left(V_{\mathrm{W}}\right) . V_{\mathrm{W}}=M_{\mathrm{W}} / 1000$, representing the corresponding water volume. $R_{\mathrm{GW}}$ is a relative criterion to assess the behavior of gas production. A high $R_{\mathrm{GW}}$ indicates a small cumulative of produced water relative to the produced gas, which means better production efficiency. As shown in Figure 10, $M_{\mathrm{W}}$ is lower than $6.22 \times 10^{6} \mathrm{~kg} / \mathrm{m}$ of well, and $R_{\mathrm{GW}}$ is larger than 7 before the 570th day. When the two wells are connected, the injected brine can be pumped out directly from the production well. Thus $M_{\mathrm{W}}$ increases to $1.95 \times 10^{7} \mathrm{~kg} / \mathrm{m}$ of well and $R_{\mathrm{GW}}$ decreases to 3.5 at the 1590 th day. After 1590 days, the injected brine can flow toward the production well with little restriction because the majority of hydrate in the reservoir has been dissociated. Consequently, $M_{\mathrm{W}}$ increases drastically and causes sharp reduction of $R_{\mathrm{GW}}$. After 30 -year production, $M_{\mathrm{W}}$ is about $2.0 \times 10^{8} \mathrm{~kg} / \mathrm{m}$ of well and $R_{\mathrm{GW}}$ is lower than 2 . 
Figure 10. Evolution of $M_{\mathrm{W}}$ and $R_{\mathrm{GW}}$ for the reference case during 30 -year production.

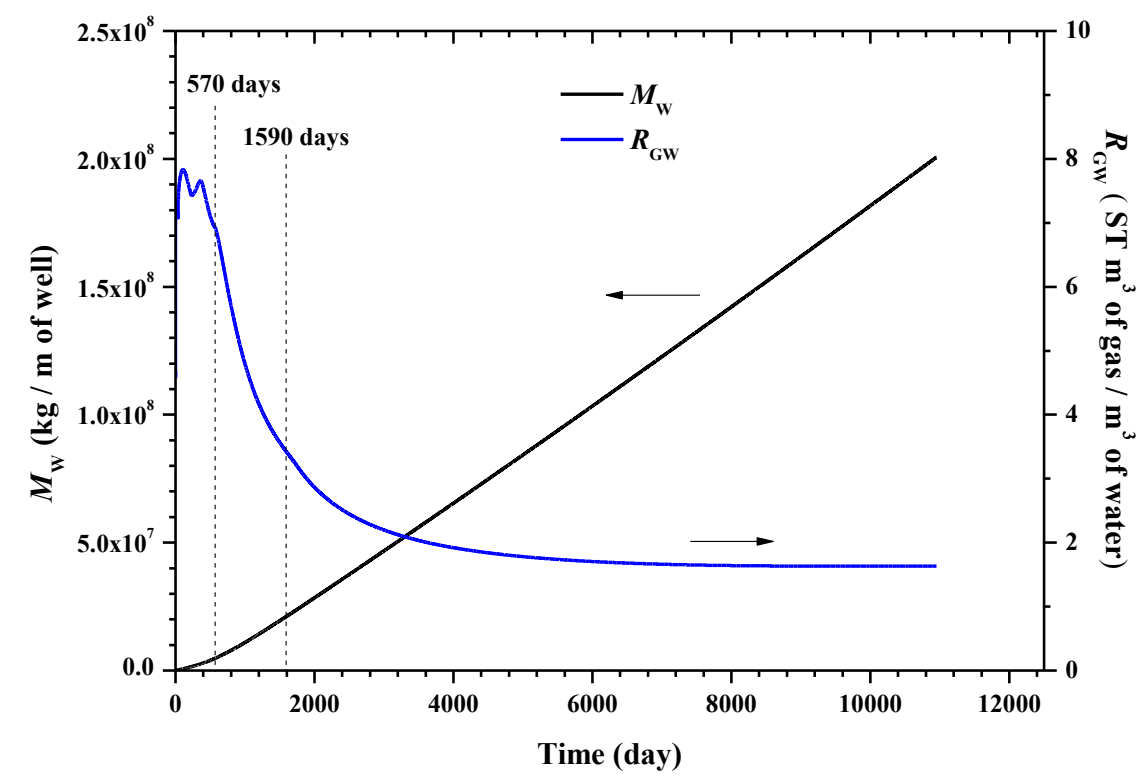

\subsubsection{Energy Ratio}

Figure 11 shows the evolution of energy ratio during 30-year production. Energy ratio is the ratio of the recovered energy to the total input energy, which can be calculated [26] as:

$$
\eta=\Delta H_{\mathrm{C}} /(W+Q)
$$

where $\Delta H_{\mathrm{c}}$ is the total combustion enthalpy of methane $\left(1 \mathrm{~atm}, 25^{\circ} \mathrm{C}, 889.6 \mathrm{~kJ} / \mathrm{mol}\right) ; W$ is the energy used for pumping the produced fluids to the ground; and $Q$ is the total energy injected into the reservoir.

Figure 11. Evolution of energy ratio for the reference case during 30-year production.

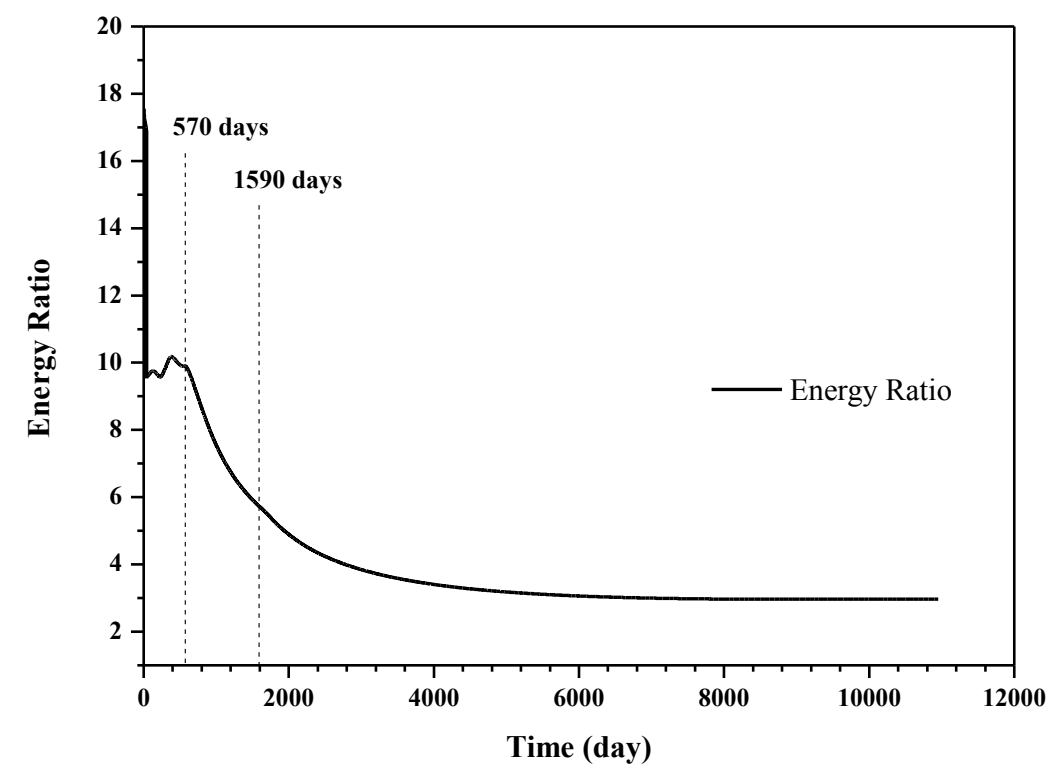

As shown in Figure 11, $\eta$ in the whole simulation process is larger than 1. In the initial 40 days, $\eta$ keeps a high level under single depressurization. When warm brine is injected into the reservoir, 
$\eta$ decreases because energy is consumed for heating the brine. Then, $\eta$ increases from the 41 st day to the 570th day due to the increase of of gas production. With the increase of water production, $\eta$ decreases to about 6 at the 1590th day. Subsequently, $\eta$ declines rapidly to about 2 at the end of simulation because of the vast amount of water production. At the 1590th day, the percentage of dissociated hydrate is about $70.5 \%$. After that, huge water production results in low level of $R_{\mathrm{GW}}$ and $\eta$, which is uneconomical. Thus, from the economic point of view, gas production can be terminated at the end of the 1590th year, which is about 5 years. In summary, it shows that the variation of all the spatial distributions is small in the later 25 years. In addition, the above analyses indicate that the majority of hydrate in the reservoir has been dissociated in the initial 1590 days. Afterward, undesirable water production causes an uneconomical gas to water ratio and energy ratio. Therefore, gas production process should be terminated or other production methods without water injection should be employed in the later 25 years.

\subsection{Comparison of the Effects of the Previous Work and the New Dual Horizontal Wells System}

In the previous work [26], the dual horizontal wells were situated in the same vertical plane, and the well configuration is described as Pattern $\mathrm{i}$ (shown in Figure 2a). We concluded that the effects of warm brine injection disappeared when the hydrate between the two wells is dissociated completely at the 118th day. The well configuration in this work is described as Pattern ii (shown in Figure 2b) in which the two wells are placed in the same horizontal plane. The two patterns represent the same region of hydrate reservoir because the area of each single unit shown in Figure 2 is the same. In the initial 40 days, the dual horizontal wells are operated under the same driving force of depressurization. Then the warm brine is injected from the lower well, meanwhile, gas and water are produced in the upper well in Pattern i. While in Pattern ii, warm brine is injected from the left well (LW), and the right well (RW) acts as the producer under constant depressurization. The driving force of depressurization and the injection rate of warm brine are the same for these two kinds of well configuration. The effects of the two kinds of well configuration are compared as follows.

\subsubsection{Gas Production and Percentage of Dissociated Hydrate}

Figure 12 shows the effects of well configuration on gas production and the dissociated gas in a year. Figure 13 shows the comparison of the percentage of dissociated hydrate between the two well configurations. In the initial 40 days, the dual horizontal wells are conducted under the same driving force of depressurization both in Pattern $i$ and Pattern ii, thus the gas production of the two patterns in the initial 40 days is the same. Subsequently, gas production occurs under the combined effects of depressurization and warm brine stimulation. The previous work concluded that the warm brine can be drawn out from the upper well directly after 118 days, and the effect of salinity is weak in the later stages of the simulation. 
Figure 12. Evolution of the effects of well configuration on gas production and the dissociated gas.

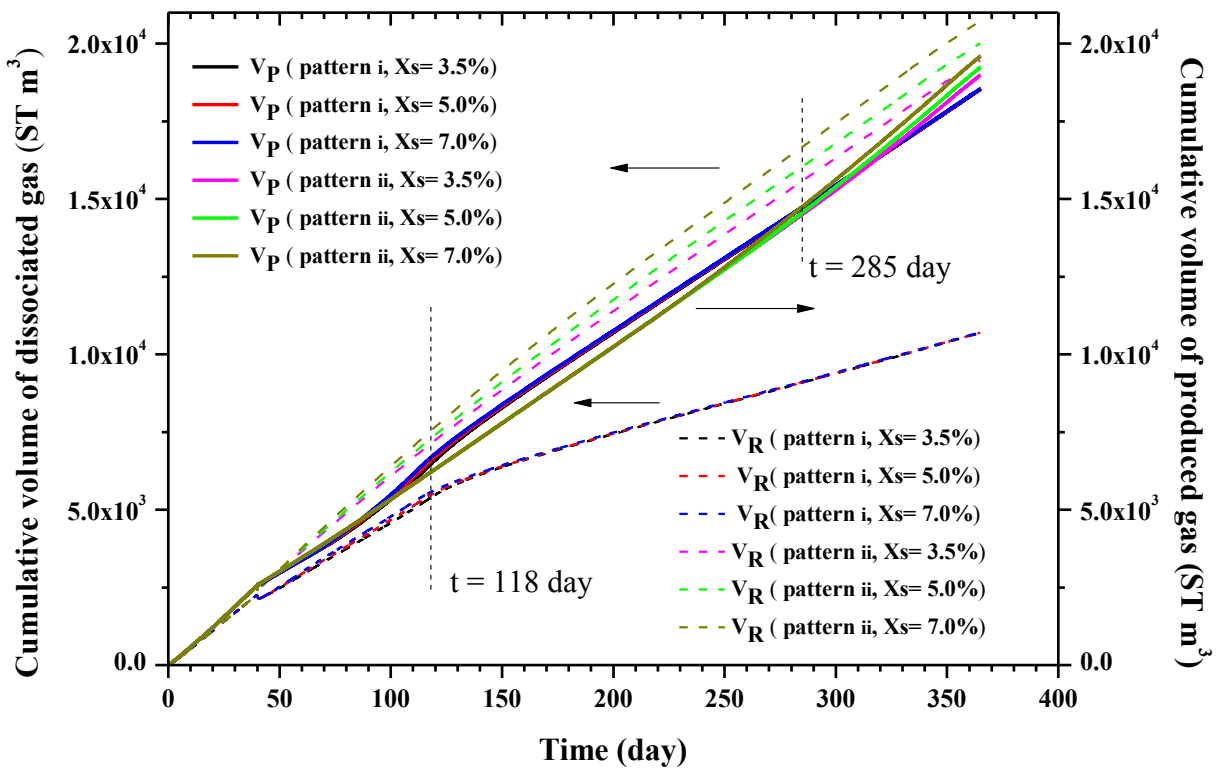

Figure 13. Evolution of the effects of well configuration on the percentage of dissociated hydrate.

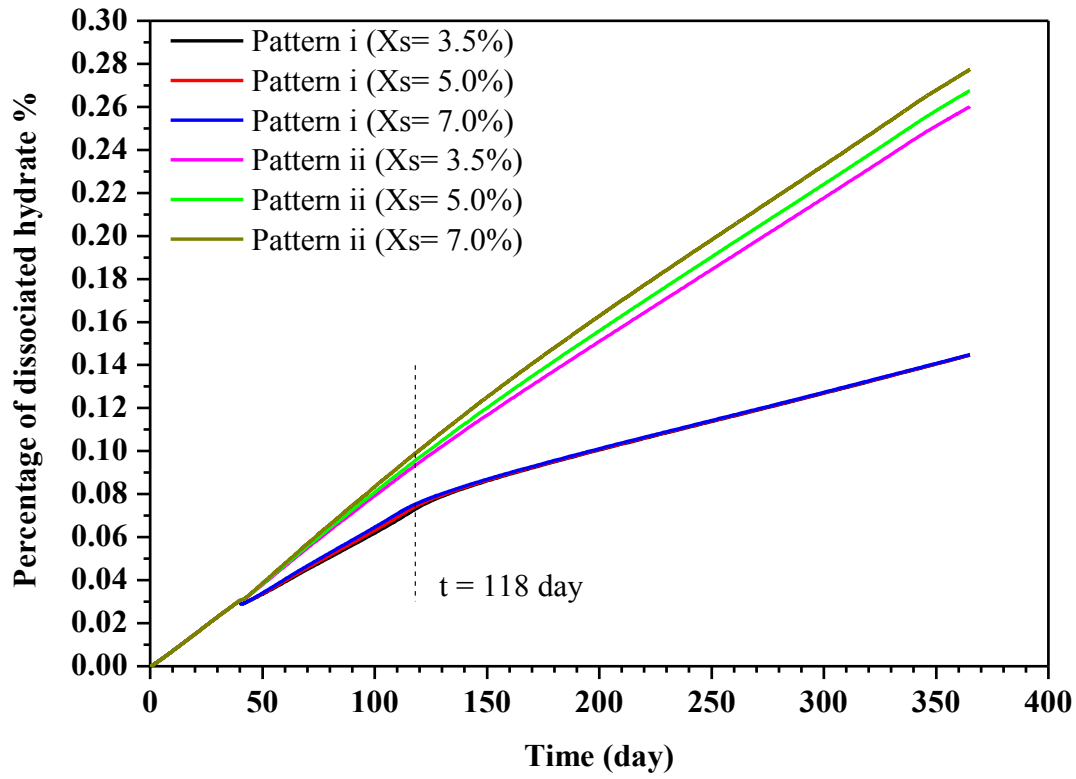

As shown in Figure 12, hydrate dissociation rate in Pattern i decreases drastically after 118 days of production, while the hydrate dissociation rate maintains its growth in Pattern ii for the whole year, and the higher salinity brine injection results in a higher dissociation rate and the hydrate dissociation rate in Pattern ii is much higher than that in Pattern i after the 118th day. In Pattern ii, the gas production rate is lower than that of hydrate dissociation rate. This is because the dissociated gas accumulates around the LW, and it needs adequate time to transfer from the LW to the RW (the production well). Gas production rate in Pattern i is higher than that in Pattern ii from the 41st day to the 285th day. The reason is that the dissociated gas can transfer from the lower well to the upper well (in Pattern i) more easily than from the left well to the right well (in Pattern ii). 
It is shown in Figure 13 that the percentage of dissociated hydrate in the new well configuration is $27.73 \%$ in a year when the salinity of the injection brine is $7.0 \%$. It is 1.92 times larger than the previous configuration. This is because the injected brine can contact with the HBL more effectively in the new well configuration.

\subsubsection{Water Production and Gas to Water Ratio}

Figures 14 and 15 show the comparisons of the effects of these two kinds of well configuration on water production and gas to water ratio $R_{\mathrm{GW}}$ in a year, respectively.

Figure 14. Evolution of the effects of well configuration on water production.

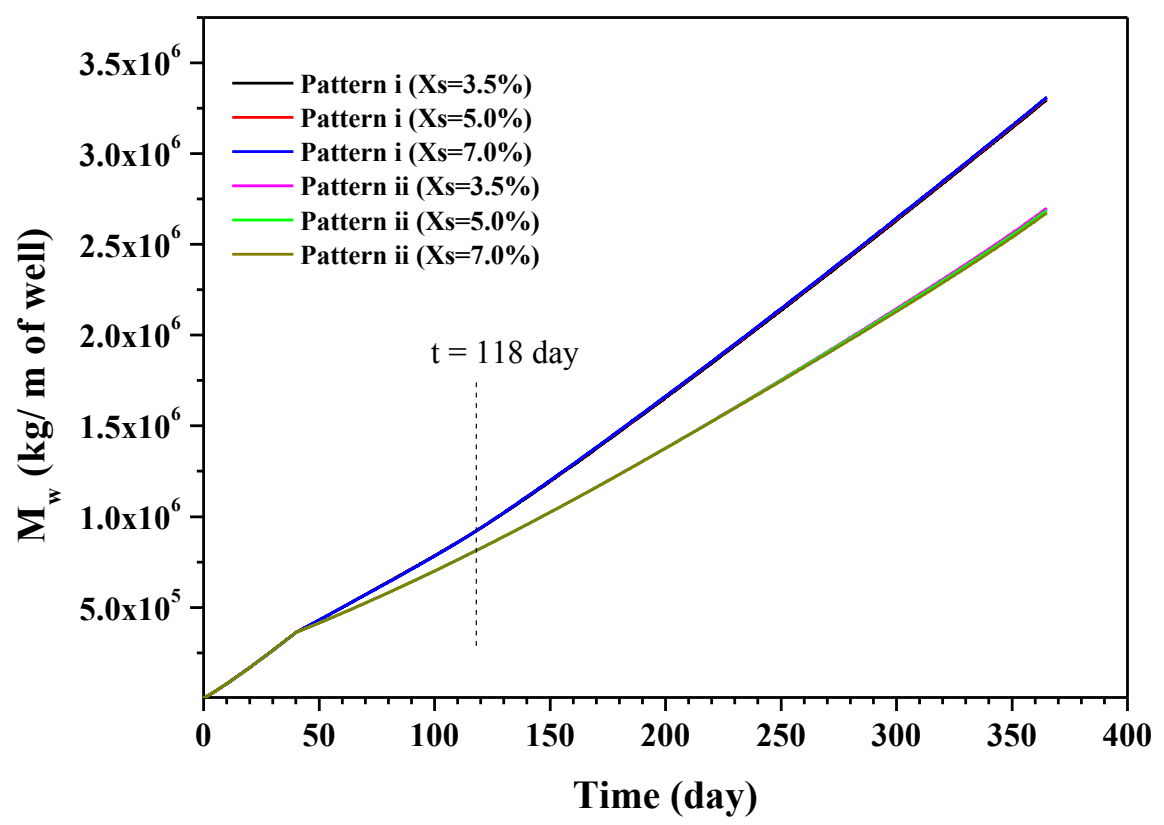

Figure 15. Evolution of the effects of well configuration on gas to water ratio.

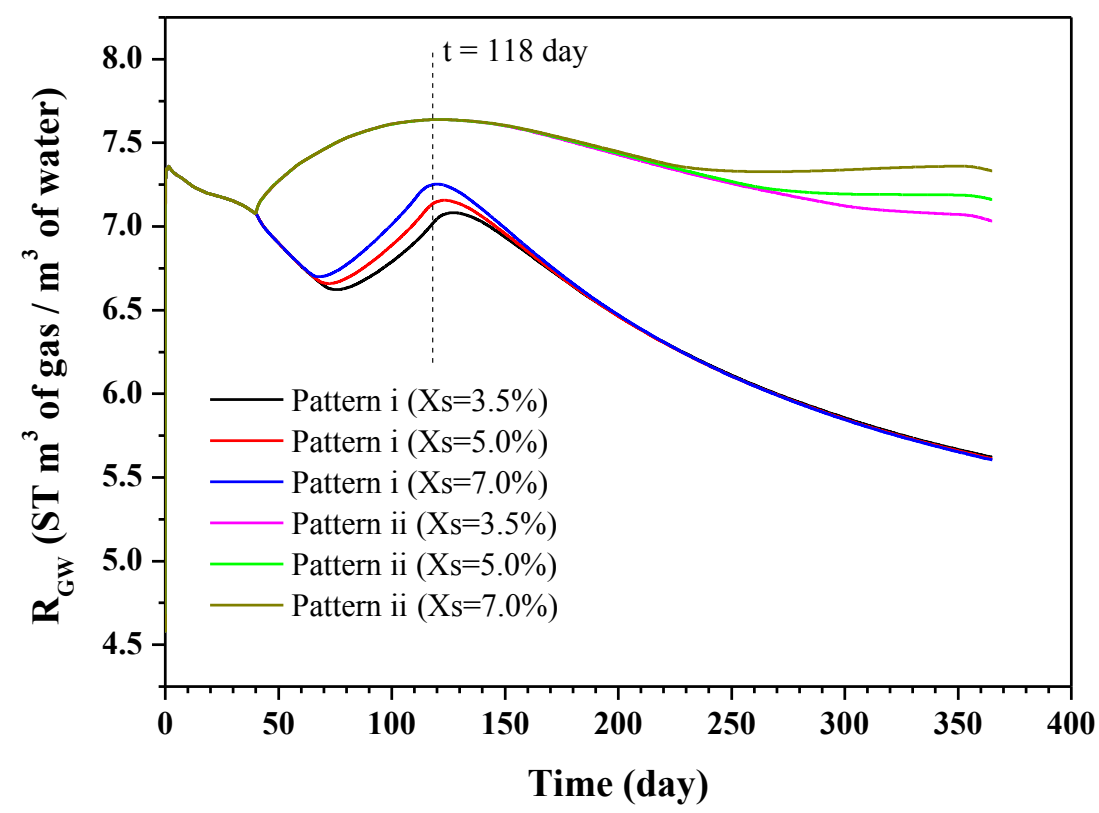


Figure 14 shows that water production in the two patterns is the same during the initial 40 days. Afterwards, water production rate in Pattern $i$ is higher than that in Pattern ii, and the difference gets larger over time. This is because the injected brine is accumulated in the hydrate reservoir in Pattern ii, however, the injected brine is pumped out from the upper well directly after the 118th day when the two wells are connected completely.

As displayed in Figure 15, in the new well configuration, on account of the abundant hydrate dissociation, $R_{\mathrm{GW}}$ increases when warm brine is injected into the reservoir. The higher salinity of the injected brine obtains a higher $R_{\mathrm{GW}}$ because the higher salinity results in larger dissociation rate of hydrate. $R_{\mathrm{GW}}$ is 7.33 in the new system in 1 year, and it is 5.61 in the previous system, which indicates that the gas production with the new well configuration is more economical than the previous work.

\subsubsection{Energy Ratio}

Figure 16 shows the comparison of the effects of the two kinds of well configuration on energy ratio. Energy ratio in the initial 40 days is remarkably higher than that when warm brine is injected into the reservoir, because gas production with the single depressurization needs no other energy source from the external environment. It indicates that from the 41st day, the curves of energy ratio in the new well configuration drop gradually to a steady stage, and the energy ratio with the highest salinity increases from the 260th day to the 365 th day. This is because the injected brine transfers from the LW to the RW, and it can effectively contact the HBL. Consequently, the hydrate of the reservoir remains at a high dissociation rate for a year (shown in Figure 3). However, the energy ratio of the previous well configuration decreases sharply to approximately 10 after 118 days. The reason is that hydrate dissociation rate drops rapidly and water production increases drastically when the two wells in the vertical plane are totally connected.

Figure 16. Evolution of the effects of well configuration on energy ratio.

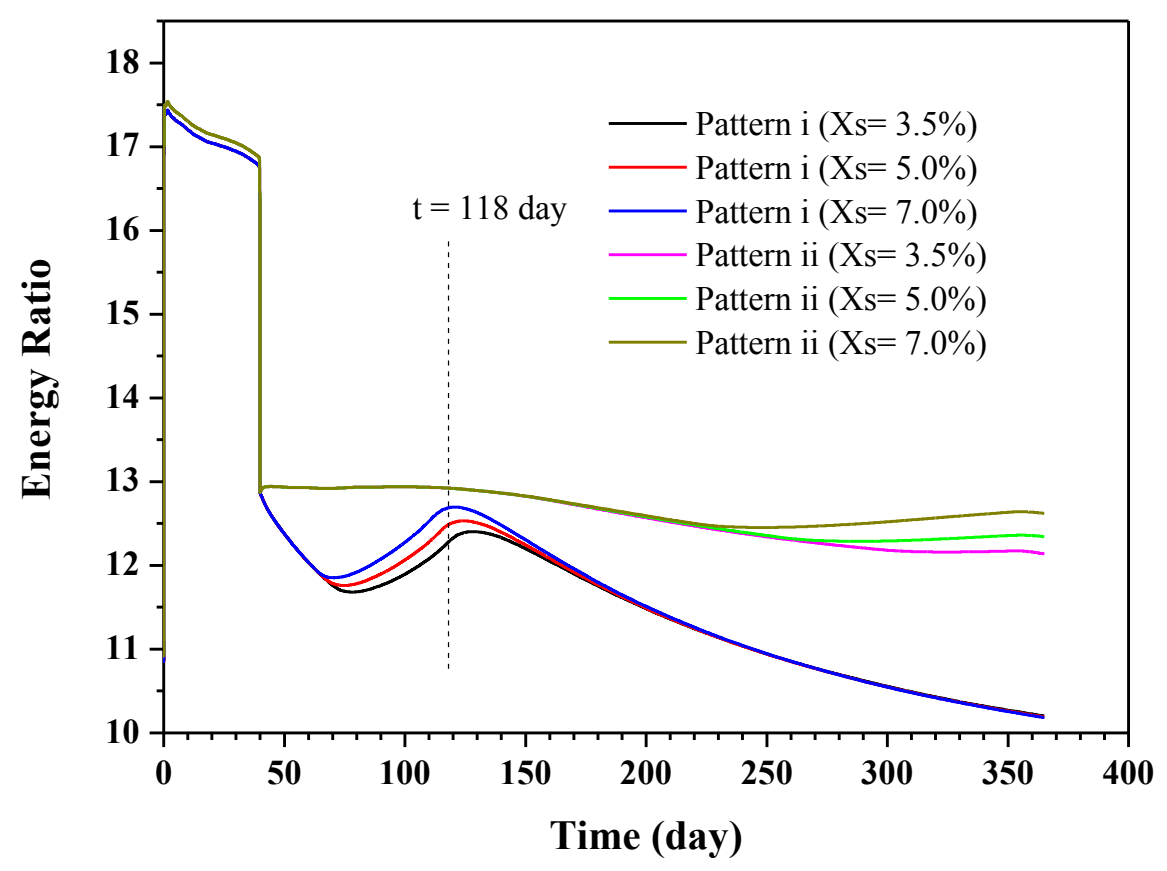


Generally, all the values of the percentage of dissociated hydrate, the gas to water ratio, and the energy ratio in the new well configuration system are higher than that in the previous work. This indicates the new well configuration is better for gas production from this hydrate reservoir.

\subsection{Sensitivity to the Injection Rate of Warm Brine $Q_{i n j}$}

Figures 17-19 display the dependence of $V_{\mathrm{P}}, V_{\mathrm{R}}, M_{\mathrm{W}}, R_{\mathrm{GW}}$, and $\eta$, on the injection rate of warm brine, respectively. Here, $Q_{\text {inj }}$ is $3.6 \mathrm{~kg} / \mathrm{s}$ in the reference case.

Figure 17. Evolution of $V_{\mathrm{P}}$ and $V_{\mathrm{R}}$, as well as their dependence on the injection rate.

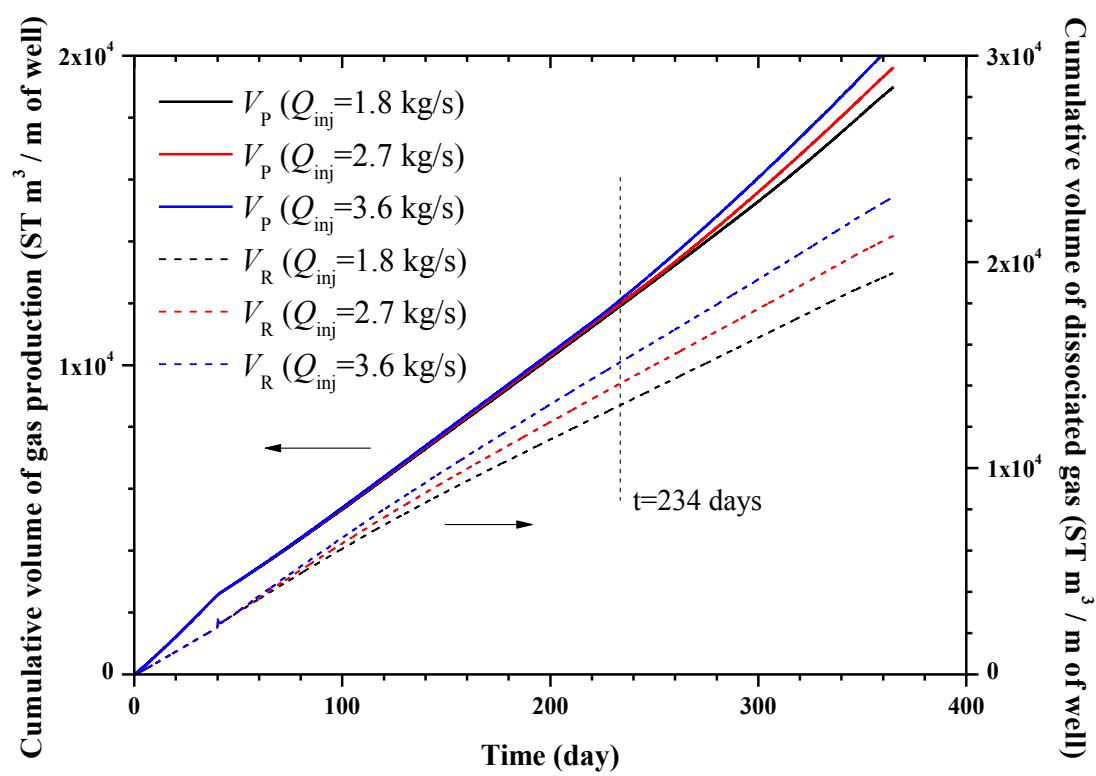

Figure 18. Evolution of $M_{\mathrm{W}}$ and $R_{\mathrm{GW}}$, as well as their dependence on the injection rate.

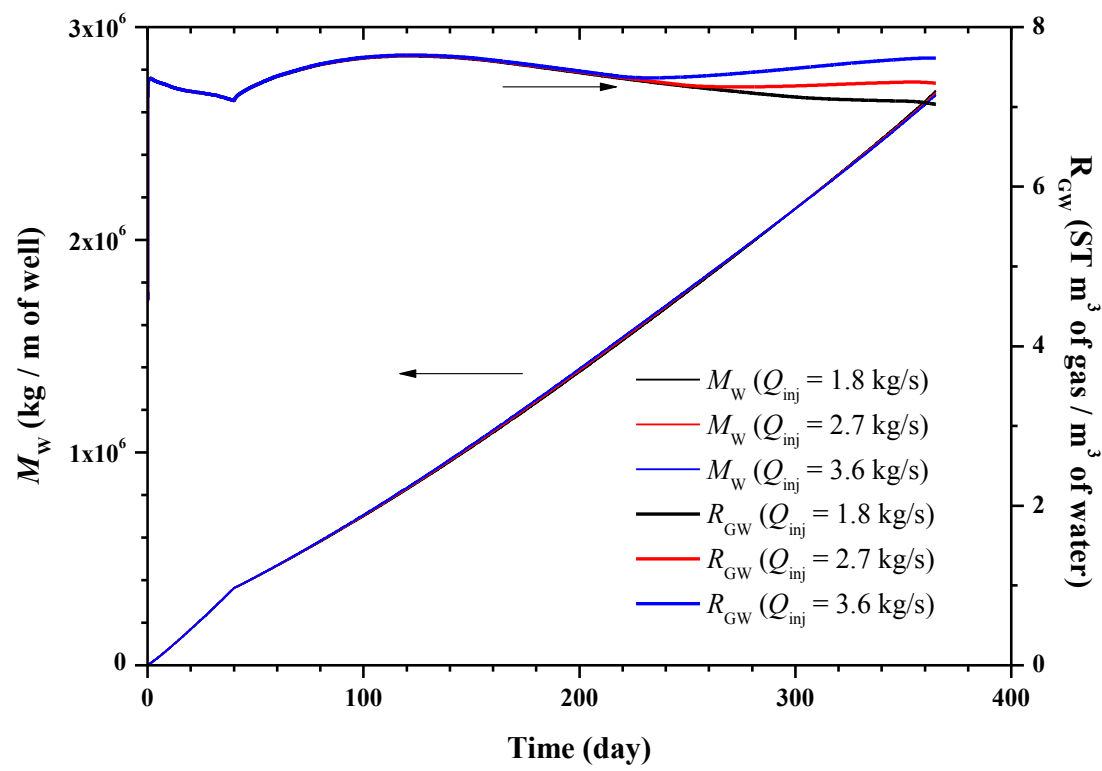


Figure 19. Evolution of $\eta$ and its dependence on the injection rate.

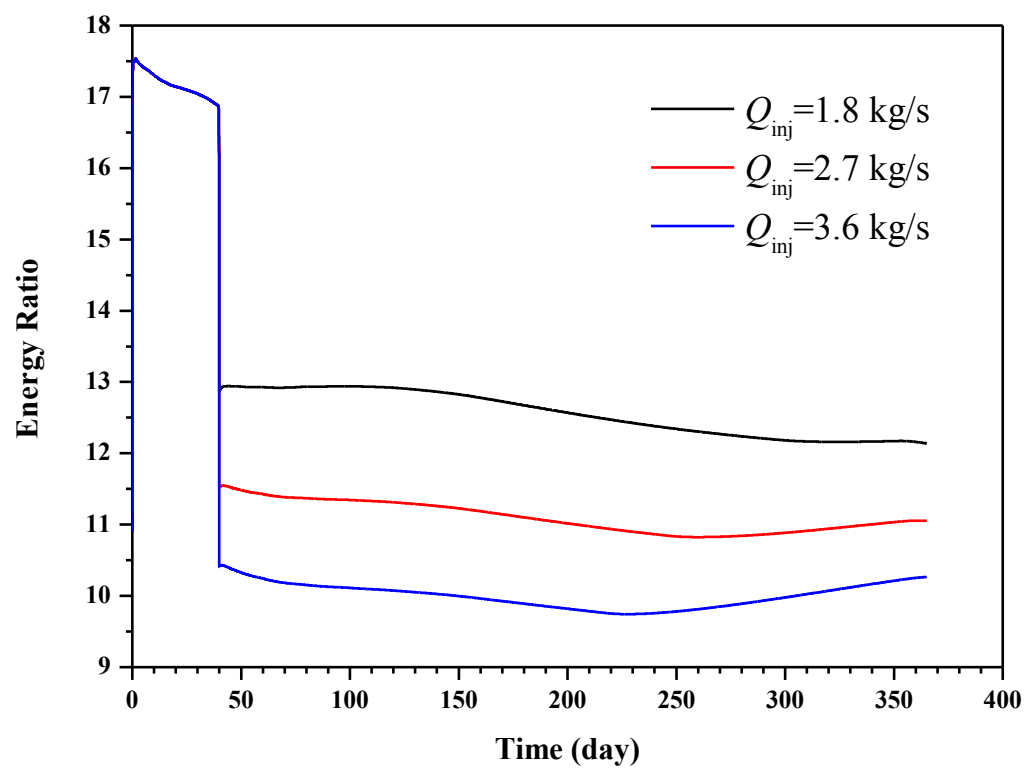

When the injection rate increases, the injected warm brine can be transferred from the LW to the inner part of the deposit more easily, and it provides more energy to dissociate the hydrate per unit time. This accelerates the dissociation rate of hydrate and increases $V_{\mathrm{R}}$ (shown in Figure 17). Although the hydrate dissociation rate rises with the increase of the injection rate, the difference of gas production among the different injection rates is small in the initial 234 days. The reason is that the dissociated gas is accumulated in the reservoir, and it needs adequate time to reach the production well. In addition, the difference of the produced water among the three cases is little (shown in Figure 18), therefore, $R_{\mathrm{GW}}$ is increased with the growth of the injection rate. On the other hand, more energy is needed to heat the injected brine with the increase of $Q_{\text {inj, }}$, and this causes the reduction of the energy ratio (shown in Figure 19). Generally, the increase of the injection rate can improve the gas production rate. On the other hand, the lower injection rate is more favorable for gas production from the point of high energy ratio.

\section{Conclusions}

A new system of dual-horizontal wells has been applied to investigate the gas production performance of the marine hydrate deposit in the South China Sea by numerical simulation. Moreover, we have compared the effects of gas production between the new system of dual-horizontal wells (the wells are located in the same horizontal plane) and a previous study (where the wells are situated in the same vertical plane). According to the simulation results, the following conclusions can be drawn:

(1) The results show that all the gas production rate, gas to water ratio, and energy ratio increase distinctly in the new well configuration because the injected warm brine can contact the hydrate reservoir more effectively.

(2) The dissociation interface around the left well (LW) grows rapidly and expands to the (RW) when warm brine is injected into the reservoir. When the two wells are connected at about the 570th day, the hydrate dissociation rate decreases because the warm brine can be pumped out 
from the RW directly. The hydrate of the entire reservoir has been dissociated $70.5 \%$ in 1590 days (4.36 years), and the average gas production rate exceeds the commercially viable production rate in the gulf of Mexico. After that, massive water production causes uneconomical gas to water ratio and energy ratio. Therefore, gas production process should be terminated or other production methods without water injection should be employed in the later 25 years.

(3) The sensitivity analysis indicates that the higher injection rate of warm brine can improve the gas production rate. However, the lower injection rate is more favorable for gas production from the point of high energy ratio.

\section{Acknowledgments}

This work is supported by National Science Fund for Distinguished Young Scholars of China (51225603), National Natural Science Foundation of China (51376183 and 51106160), Key Arrangement Programs of the Chinese Academy of Sciences (KGZD-EW-301-2), and Science \& Technology Program of Guangzhou (2012J5100012), which are gratefully acknowledged.

\section{Notations}

$G \quad$ thermal gradient within the sea $\left({ }^{\circ} \mathrm{C} / \mathrm{m}\right)$

$H \quad$ depth of the sea water (m)

$k \quad$ intrinsic permeability $\left(\mathrm{m}^{2}\right)$

$k_{\text {eff }} \quad$ effective permeability $\left(\mathrm{m}^{2}\right)$

$k_{\mathrm{rA}} \quad$ aqueous relative permeability $\left(\mathrm{m}^{2}\right)$

$k_{\mathrm{rG}} \quad$ gas relative permeability $\left(\mathrm{m}^{2}\right)$

$k_{\Theta \mathrm{C}} \quad$ thermal conductivity $(\mathrm{W} / \mathrm{m} / \mathrm{K})$

$k_{\Theta \mathrm{RD}} \quad$ thermal conductivity of dry porous medium $(\mathrm{W} / \mathrm{m} / \mathrm{K})$

$k_{\Theta \mathrm{RW}} \quad$ thermal conductivity of fully saturated porous medium $(\mathrm{W} / \mathrm{m} / \mathrm{K})$

$k_{\Theta I} \quad$ thermal conductivity of ice $(\mathrm{W} / \mathrm{m} / \mathrm{K})$

$V_{\mathrm{P}} \quad$ cumulative volume of produced gas $\left(\mathrm{m}^{3}\right)$

$V_{\mathrm{R}} \quad$ cumulative volume of released gas $\left(\mathrm{m}^{3}\right)$

$M_{\mathrm{W}} \quad$ cumulative mass of produced water $(\mathrm{kg})$

$P \quad$ pressure $(\mathrm{MPa})$

$P_{\mathrm{B}} \quad$ initial pressure at base of $\mathrm{HBL}(\mathrm{MPa})$

$P_{0} \quad$ atmosphere pressure $(\mathrm{MPa})$

$P_{\mathrm{W}} \quad$ pressure at the well (MPa)

$P_{\text {Wo }} \quad$ initial pressure at the well (MPa)

$Q \quad$ injected heat (J)

$Q_{\text {avg }} \quad$ average gas production rate ( $\mathrm{ST} \mathrm{m}^{3} /$ day $/ \mathrm{m}$ of well)

$Q_{\text {inj }} \quad$ heat injection rate $(\mathrm{W} / \mathrm{m}$ of well)

$r \quad$ radius (m)

$R_{\mathrm{GW}} \quad$ the gas to water production ratio $\left(\mathrm{ST} \mathrm{m}^{3}\right.$ of $\mathrm{CH}_{4} / \mathrm{m}^{3}$ of $\left.\mathrm{H}_{2} \mathrm{O}\right)$

$S \quad$ phase saturation

$t \quad$ time (days) 
$T \quad$ temperature $\left({ }^{\circ} \mathrm{C}\right)$

$T_{0} \quad$ the temperature of the sea floor $\left({ }^{\circ} \mathrm{C}\right)$

$T_{\mathrm{W}} \quad$ injected warm water temperature $\left({ }^{\circ} \mathrm{C}\right)$

$T_{\mathrm{B}} \quad$ initial temperature at the base of $\operatorname{HBL}\left({ }^{\circ} \mathrm{C}\right)$

$T_{\mathrm{T}} \quad$ initial temperature at the top of HBL $\left({ }^{\circ} \mathrm{C}\right)$

$W \quad$ pump work (J)

$x, y, z \quad$ cartesian coordinates (m)

$S_{\mathrm{H}} \quad$ hydrate saturation

$S_{\mathrm{G}} \quad$ gas saturation

$X_{\mathrm{S}}$ the mass fraction of salt in the aqueous phase

$\Delta H_{\mathrm{c}} \quad$ combustion enthalpy of produced methane (J)

$\Delta P_{\mathrm{W}} \quad$ driving force of depressurization, $P_{\mathrm{W} 0}-P_{\mathrm{W}}(\mathrm{MPa})$

$\Delta x \quad$ discretization along the $x$-axis (m)

$\Delta y \quad$ discretization along the $y$-axis (m)

$\Delta z \quad$ discretization along the $z$-axis (m)

$\phi \quad$ porosity

$\eta \quad$ energy ratio

$\lambda \quad$ van Genuchten exponent-Table 1

Subscripts and Superscripts

0 denotes initial state

A aqueous phase

B base of HBL

cap capillary

G gas phase

$\mathrm{H} \quad$ solid hydrate phase

\section{Author Contributions}

All the authors contributed to publish this paper. Jing-Chun Feng, Gang Li, Bo Li, and Yi Wang mainly established the model of this paper. Jing-Chun Feng has carried out the simulation tests and Bo Li has checked the simulation result. Writing was done by Jing-Chun Feng, Bo Li, and Yi Wang. Final review was done by Xiao-Sen Li, Gang Li, and Zhao-Yang Chen.

\section{Conflicts of Interest}

The authors declare no conflict of interest.

\section{References}

1. Sloan, E.D.; Koh, C.A. Clathrate Hydrates of Natural Gases, 3rd ed.; CRC Press: Boca Raton, FL, USA, 2008.

2. Moridis, G.J.; Collett, T.S.; Boswell, R.; Kurihara, M.; Reagan, M.T.; Koh, C.; Sloan, E.D. Toward production from gas hydrates: current status, assessment of resources, and simulation-based evaluation of technology and potential. SPE Reserv. Eval. Eng. 2009, 12, 745-771. 
3. Li, X.S.; Zhang, Y.; Li, G.; Chen, Z.Y.; Wu, H.J. Experimental investigation into the production behavior of methane hydrate in porous sediment by depressurization with a novel three-dimensional cubic hydrate simulator. Energy Fuels 2011, 25, 4497-4505.

4. Li, G.; Li, B.; Li, X.S.; Zhang, Y.; Wang, Y. Experimental and numerical studies on gas production from methane hydrate in porous media by depressurization in pilot-scale hydrate simulator. Energy Fuels 2012, 26, 6300-6310.

5. Li, X.S.; Yang, B.; Zhang, Y.; Li, G.; Duan, L.P.; Wang, Y. Experimental investigation into gas production from methane hydrate in sediment by depressurization in a novel pilot-scale hydrate simulator. Appli. Energy 2012, 93, 722-732.

6. Konno, Y.; Masuda, Y.; Hariguchi, Y.; Kurihara, M.; Ouchi, H. Key factors for depressurization-induced gas production from oceanic methane hydrates. Energy Fuels 2010, 24, 1736-1744.

7. Cef, H.; Praveen, L.; John, A.R.; Peter, E. Recovery of methane from a variable-volume bed of silica sand/hydrate by depressurization. Energy Fuels 2010, 24, 2947-2955.

8. Wang, Y.; Li, X.S.; Li, G.; Zhang, Y.; Li, B.; Chen, Z.Y. Experimental investigation into methane hydrate production during three-dimensional thermal stimulation with five-spot well system. Appl. Energy 2013, 110, 90-97.

9. Fitzgerald, G.C.; Castaldi, M.J.; Zhou, Y. Large scale reactor details and results for the formation and decomposition of methane hydrates via thermal stimulation dissociation. J. Petrol. Sci. Eng. 2012, 94, 19-27.

10. Wang, Y.; Li, X.S.; Li, G.; Huang, N.S.; Feng, J.C. Experimental study on the hydrate dissociation in porous media by five-spot thermal huff and puff method. Fuel 2014, 117, 688-696.

11. Li, G.; Moridis, G.J.; Zhang, K.; Li, X.S. The use of huff and puff method in a single horizontal well in gas production from marine gas hydrate deposits in the Shenhu Area of South China Sea. J. Petrol. Sci. Eng. 2011, 77, 49-68.

12. Praveen, L.; Cef, H.; Sung, C.N.; John, A.R.; Peter, E. Recovery of methane from hydrate formed in a variable volume bed of silica sand particles. Energy Fuels 2009, 23, 5508-5516.

13. Prathyusha, M.; Ponnivalavan, B.; Jitendra, S.S.; Praveen, L. Formation and dissociation kinetics of methane hydrates in seawater and silica sand. Energy Fuels 2014, 28, 2708-2716.

14. Li, G.; Li, X.S.; Tang, L.G.; Zhang, Y.; Feng, Z.P.; Fan, S.S. Experimental investigation of production behavior of methane hydrate under ethylene glycol injection. J. Chem. Ind. Eng. (China) 2007, 58, 2067-2074.

15. Sung, W.M.; Lee, H.; Lee, C. Numerical study for production performances of a methane hydrate reservoir stimulated by inhibitor injection. Energy Sources 2002, 24, 499-512.

16. Kawamura, T.; Yamamoto, Y.; Ohtake, M.; Sakamoto, Y.; Komai, T.; Haneda, H. Experimental study on dissociation of hydrate core sample accelerated by thermodynamic inhibitors for gas recovery from natural gas hydrate. In Proceedings of the 5th International Conference on Gas Hydrate, Trondheim, Norway, 12-16 June 2005.

17. Li, X.S.; Wan, L.H.; Li, G.; Li, Q.P.; Chen, Z.Y.; Yan, K.F. Experimental investigation into the production behavior of methane hydrate in porous sediment with hot brine stimulation. Ind. Eng. Chem. Res. 2008, 47, 9696-9702. 
18. Zhou, X.T.; Fan, S.S.; Liang, D.Q.; Du, J.W. Replacement of methane from quartz sand-bearing hydrate with carbon dioxide-in-water emulsion. Energy Fuels 2008, 22, 1759-1764.

19. Lee, S.; Lee, Y.; Lee, J.; Lee, H.; Seo, Y. Experimental verification of methane-carbon dioxide replacement in natural gas hydrates using a differential scanning calorimeter. Environ. Sci. Technol. 2013, 47, 13184-13190.

20. Li, X.S.; Wang, Y.; Li, G.; Zhang, Y. Experimental investigations into gas production behaviors from methane hydrate with different methods in a cubic hydrate simulator. Energy Fuels 2012, $26,1124-1134$.

21. Trung, N.N. The gas hydrate potential in the South China Sea. J. Petrol. Sci. Eng. 2012, 88, 41-47.

22. Hu, G.; Ye, Y.; Zhang, J.; Liu, C.; Li, Q. Acoustic response of gas hydrate formation in sediments from South China Sea. Mar. Pet. Geol. 2014, 52, 1-8.

23. Wang, C.J.; Du, D.W.; Zhu, Z.W.; Liu, Y.G.; Yan, S.J.; Yang, G. Estimation of potential distribution of gas hydrate in the northern South China Sea. Chin. J. Oceanol. Limnol. 2010, 28, 693-699.

24. Wu, N.Y.; Zhang, H.Q.; Yang, S.X.; Liang, J.Q.; Wand, H.B. Preliminary discussion on natural gas hydrate (NGH) reservoir system of shenhu area, north slope of south china sea. Nat. Gas Ind. 2007, 27, 1-6.

25. Su, Z.; Moridis, G.J.; Zhang, K.N.; Wu, N.Y. A huff-and-puff production of gas hydrate deposits in Shenhu area of South China Sea through a vertical well. J. Petrol. Sci. Eng. 2012, 86, 54-61.

26. Feng, J.C.; Li, G.; Li, X.S.; Li, B.; Chen, Z.Y. Evolution of hydrate dissociation by warm brine stimulation combined depressurization in the south china sea. Energies 2013, 6, 5402-5425.

27. Moridis, G.J.; Reagan, M.T. Strategies for gas production from oceanic class 3 hydrate accumulations. In Proceedings of the Offshore Technology Conference, Houston, TX, USA, 30 April-3 May 2007.

28. Vanoudheusden, E.; Sultan, N.; Cochonat, P. Mechanical behaviour of unsaturated marine sediments: Experimental and theoretical approaches. Mar. Geol. 2004, 213, 323-342.

29. Moridis, G.J.; Kowalsky, M.B.; Pruess, K. Tough+Hydrate v1.1 User's Manual: A Code for the Simulation of System Behavior in Hydrate-Bearing Geologic Media; Lawrence Berkeley National Laboratory: Berkeley, CA, USA, 2009.

30. Li, G.; Li, X.S.; Li, B.; Wang, Y. Methane hydrate dissociation using inverted five-spot water flooding method in cubic hydrate simulator. Energy 2014, 64, 298-306.

31. Li, B.; Li, X.S.; Li, G. Kinetic studies of methane hydrate formation in porous media based on experiments in a pilot-scale hydrate simulator and a new model. Chem. Eng. Sci. 2014, 105, 220-230.

32. Li, X.S.; Li, B.; Li, G.; Yang, B. Numerical simulation of gas production potential from permafrost hydrate deposits by huff and puff method in a single horizontal well in Qilian Mountain, Qinghai province. Energy 2012, 40, 59-75.

33. Moridis, G.J. Reagan, M.T. Boyle, K.L. Zhang, K.N. Evaluation of the gas production potential of some particularly challenging types of oceanic hydrate deposits. Transp. Porous Med. 2011, 90, 269-299.

(C) 2014 by the authors; licensee MDPI, Basel, Switzerland. This article is an open access article distributed under the terms and conditions of the Creative Commons Attribution license (http://creativecommons.org/licenses/by/3.0/). 